\title{
Mid-infrared spectroscopy of alkali feldspar samples for space application
}

\author{
Maximilian P. Reitze ${ }^{1}$ (D ) Iris Weber ${ }^{1} \cdot$ Herbert Kroll $^{2} \cdot$ Andreas Morlok $^{1} \cdot$ Harald Hiesinger $^{1} \cdot$ Jörn Helbert $^{3}$
}

Received: 18 November 2019 / Accepted: 18 May 2020 / Published online: 30 July 2020

(C) The Author(s) 2020

\begin{abstract}
Feldspars are major components of terrestrial planetary surfaces. For future space application and the setup of a comprehensive reference database, Na- and K-rich alkali feldspars, $\mathrm{NaAlSi}_{3} \mathrm{O}_{8}-\mathrm{KAlSi}_{3} \mathrm{O}_{8}$, have been investigated by infrared reflectance spectroscopy. We related the feldspar spectra to the chemical composition and state of $\mathrm{Al}, \mathrm{Si}$ order/disorder. The infrared measurements were analyzed with respect to band shifts and peak shapes using the autocorrelation function. Natural samples served as starting materials. Some samples were treated by the alkali exchange method to produce pure end-members, which were then heated to generate various states of Al,Si disorder. X-ray diffraction (XRD) methods served to determine the $\mathrm{Al}, \mathrm{Si}$ distribution. Our autocorrelation allowed to differentiate between the compositional and the order/disorder influences seen in the spectra in the wavelength range between $7 \mu \mathrm{m}$ up to $14 \mu \mathrm{m}$ $\left(1429 \mathrm{~cm}^{-1}\right.$ to $\left.714 \mathrm{~cm}^{-1}\right)$. Space missions often analyze the surfaces of planetary bodies using remote sensing. Therefore, our results are essential to characterize and distinguish alkali feldspars on the surfaces of terrestrial planetary bodies like Mercury.
\end{abstract}

Keywords Alkali feldspars $\cdot$ Infrared spectroscopy $\cdot$ X-ray diffraction $\cdot$ Al,Si distribution

\section{Introduction}

Feldspars are rock-forming minerals, on Earth and on other terrestrial planetary bodies. In the Earth's crust, they account for more than 50 vol\% (Okrusch and Matthes 2014). Lunar highlands, which cover approximately $83 \%$ of the lunar surface (Jolliff et al. 2006), are composed mostly of anorthosites and gabbros with a large amount of anorthite (Wood et al. 1970). Furthermore, Mercury's crust is feldspatic with a labradorite-like composition predicated on the basis of Earth-based infrared emission spectroscopy by Sprague et al. (1997), who measured a Christiansen

Editorial handling: A. Beran

Maximilian P. Reitze

maximilian.p-reitze@uni-muenster.de

1 Institut für Planetologie, Westfälische Wilhelms-Universität, Wilhelm-Klemm-Str. 10, 48149, Münster, Germany

2 Institut für Mineralogie, Westfälische Wilhelms-Universität, Corrensstr. 24, 48149, Münster, Germany

3 Deutsches Zentrum für Luft- und Raumfahrt, Rutherfordstr. 2, 12489 , Berlin, Germany feature (CF) at $8 \mu \mathrm{m}\left(1250 \mathrm{~cm}^{-1}\right)$ near the equator at approximately $120^{\circ}$ longitude. After spectral unmixing of Earth-based observations, Mercury's surface is thought to contain potassium-rich feldspar (Sprague et al. 2009).

Direct sampling of Solar System bodies other than Earth requires landing on the surface and returning samples, which is extremely expensive and currently not feasible for most objects. Thus, remote sensing data of planets and moons are necessary to provide the missing information.

Between 2011 and 2015, the MESSENGER (MErcury Surface, Space ENvironment, GEochemistry and Ranging) mission investigated the hermean surface (see Solomon et al. 2018, for a detailed description). The gamma-ray spectrometer (GRS) onboard the MESSENGER mission measured high $\mathrm{Mg} / \mathrm{Si}$ and low $\mathrm{Al} / \mathrm{Si}$ and $\mathrm{Ca} / \mathrm{Si}$ contents, which excludes an anorthite-rich feldspatic crust like the lunar highlands (Nittler et al. 2011). GRS detected relatively high abundances of sodium, which suggest that albite is a major mineral on the surface of Mercury (Evans et al. 2012).

In October 2018, the ESA/JAXA BepiColombo spacecraft was launched to investigate the innermost planet of our Solar System via remote sensing. Among several other instruments, MERTIS (MErcury Radiometer and Thermal Infrared Spectrometer) will investigate Mercury's surface 
in the mid-infrared (mid-IR) wavelength region (Hiesinger et al. 2010; H. Hiesinger and co-workers, in preparation). The goals of MERTIS are to study the surface mineralogy and composition, to map the mineralogy, and to measure the surface temperatures as well as the thermal inertia (Hiesinger et al. 2010; H. Hiesinger and co-workers, in preparation). To achieve these goals, MERTIS operates in the wavelength region from $7 \mu \mathrm{m}$ to $14 \mu \mathrm{m}$ (Spectrometer Channels/TIS $1429 \mathrm{~cm}^{-1}$ to $714 \mathrm{~cm}^{-1}$ ) and from $7 \mu \mathrm{m}$ to $40 \mu \mathrm{m}$ (Radiometer Channels/TIR $1429 \mathrm{~cm}^{-1}$ to $250 \mathrm{~cm}^{-1}$ ) (Hiesinger et al. 2010; H. Hiesinger and co-workers, in preparation).

Reflectance and absorption are not directly convertible (e.g., Kirkland et al. 2002; Thomson and Salisbury 1993). Therefore to apply spectral deconvolution algorithms we need reflectance spectra, which are comparable to remotely acquired data for the remote sensing applications.

For the interpretation of data returned from space missions, laboratory work is essential. Known factors which control reflectance and emission mid-IR data are, for example, the chemical composition, grain size distribution, bulk sample density, viewing geometry, pressure, and temperature (e.g., Pieters and Englert 1993). In this context, analyses of different grain sizes are necessary, because the surfaces of atmosphereless planetary bodies, like Mercury, are highly affected by larger and smaller impacts, which cause the formation of a poorly-sorted regolith.

To setup our spectral database that is valuable for remote sensing of various Solar System bodies, it is necessary to investigate well characterized samples of the alkali feldspar system. This includes both chemical composition and degree of $\mathrm{Al}, \mathrm{Si}$ order in addition to other known factors controlling the shape of mid-IR spectra (Weber et al. 2018).

The study of feldspars includes their formation conditions, occurrences, chemical, and physical behaviors. Alkali feldspars are solid solutions of the end-members $\mathrm{K}\left[\mathrm{AlSi}_{3} \mathrm{O}_{8}\right]$ (Or) and $\mathrm{Na}\left[\mathrm{AlSi}_{3} \mathrm{O}_{8}\right](\mathrm{Ab})$. They mostly contain small amounts of $\mathrm{Ca}\left[\mathrm{Al}_{2} \mathrm{Si}_{2} \mathrm{O}_{8}\right](\mathrm{An})$. In addition to their chemical compositions, they are characterized by the specific distributions of $\mathrm{Al}$ and $\mathrm{Si}$ onto the tetrahedral sites of their framework structures ("structural state"). The most common rock-forming alkali feldspars, ranging in composition from $\mathrm{Or}_{100} \mathrm{Ab}_{0}$ to $\mathrm{Or}_{30} \mathrm{Ab}_{70}$, occur in two different modifications. Monoclinic sanidine $(\mathrm{K}, \mathrm{Na})\left[\mathrm{AlSi}_{3} \mathrm{O}_{8}\right]$ is the stable modification at high temperatures. The $\mathrm{Al}$ and $\mathrm{Si}$ atoms (1 Al plus $3 \mathrm{Si}$ per formula unit) are distributed in a highly disordered, but not completely random manner onto two $\mathrm{T}_{1}$ and two $\mathrm{T}_{2}$ tetrahedral sites. The larger $\mathrm{Al}$ atom slightly prefers the $\mathrm{T}_{1}$ over the $\mathrm{T}_{2}$ site (Scambos et al. 1987), denoted by $\mathrm{t}_{1}>\mathrm{t}_{2}$ with $\mathrm{t}=\mathrm{Al} /(\mathrm{Al}+\mathrm{Si})$ of the respective site (Kroll 1973). Provided a rate-enhancing influence being present, such as a fluid phase, mineral-fluid replacement processes lead at $\mathrm{T} \leq 450{ }^{\circ} \mathrm{C}-480^{\circ} \mathrm{C}$ to the triclinic modification of microcline that under the polarizing microscope shows a characteristic tartan twinning reflecting the loss of monoclinic symmetry elements (Parsons 1978). The phase transition causes the $\mathrm{T}_{1}$ and $\mathrm{T}_{2}$ sites to split into $\mathrm{T}_{1} 0$, $\mathrm{T}_{1} \mathrm{~m}$ and $\mathrm{T}_{2} 0, \mathrm{~T}_{2} \mathrm{~m}$ sites, respectively. Aluminum concentrates in the $\mathrm{T}_{1} 0$ site so that at full order $\mathrm{t}_{1} 0=1, \mathrm{t}_{1} \mathrm{~m}=$ $\mathrm{t}_{2} \mathrm{O}=\mathrm{t}_{2} \mathrm{~m}=0$. At less favorable conditions, due to the high kinetic Al,Si exchange barrier, the transition results in a kinetically stranded, metastable pseudomorph called orthoclase. On a submicroscopic scale, orthoclase consists of intimately intergrown triclinic domains. All textural stages between orthoclase and microcline may be present in one and the same morphological unit. Na-rich alkali feldspars are as well symmetrically monoclinic at high temperature (monalbite). Changes to triclinic symmetry are induced during cooling through two different, though coupled mechanisms: A displacive transition at $980{ }^{\circ} \mathrm{C}$, followed by a continuous $\mathrm{Al}, \mathrm{Si}$ ordering process (Salje et al. 1985). On slow cooling, Al,Si ordering proceeds at $\mathrm{T}<980{ }^{\circ} \mathrm{C}$ in the triclinic state with $\mathrm{Al}$ gradually enriched in the $\mathrm{T}_{1} 0$ site while leaving the other three sites so that in the end $\mathrm{t}_{1} 0=1$, $\mathrm{t}_{1} \mathrm{~m}=\mathrm{t}_{2} \mathrm{O}=\mathrm{t}_{2} \mathrm{~m}=0$ like in microcline. By contrast, when rapidly cooled, monalbite collapses to triclinic metastable analbite because the $\mathrm{Na}$ ion is too small to prevent structural collapse in contrast to the larger $\mathrm{K}$ ion in sanidine. The terms high albite and low albite denote different states of order. At high temperatures, the solid solution series between monalbite and sanidine is continuous. A wide miscibility gap opens at lower temperatures, leading to the formation of intimately intergrown phase segregation textures of which perthites (Na-feldspar in a matrix of K-feldspar) are most common (Okrusch and Matthes 2014, and referenes therein).

Characteristics of alkali feldspars concerning the structure, formation conditions, exsolution processes, and behavior at high temperatures are well known (e.g., Ribbe 1983). Previous infrared spectroscopy work on the feldspar system shows that changes in absorption spectra occur according to chemical composition and degree of Al,Si order (e.g., Laves and Hafner 1956; Hafner and Laves 1957; Martin 1970; Zhang et al. 1996, 1997). Hecker et al. (2010) gave a review of different infrared techniques and their usefulness for remote sensing application. Iiishi et al. (1971) correlated single bands in K-feldspar absorption spectra between $8.7 \mu \mathrm{m}$ and $23.3 \mu \mathrm{m}\left(1150 \mathrm{~cm}^{-1}\right.$ and $\left.430 \mathrm{~cm}^{-1}\right)$ with specific stretching, bending, translation, and expansion/contraction vibrations of $\mathrm{Si}-\mathrm{O}, \mathrm{Si}-\mathrm{Si}$, and $\mathrm{Si}-\mathrm{O}-\mathrm{Si}$ bonds, which are controlled by the state of Al,Si order. However, most of the bands described by Iiishi et al. (1971) cannot be observed as single peaks in powder reflectance spectra.

The objective of our study is to measure mid-IR powder reflectance spectra of well characterized alkali feldspar 
samples to build a database for remote sensing applications. This database is necessary especially for MERTIS.

\section{Samples and analyses}

\section{Samples}

To differentiate and quantify controlling factors of the powder mid-IR reflectance spectra, the analyzed samples must be well characterized. Natural alkali feldspars were used as raw materials, which were first thoroughly characterized and then treated in different ways described in the subsection "Sample Treatment". All samples presented in this study, both natural and treated, have an internal database identification number (ID, Table 1), which refers to our database which is accessible at www.uni-muenster. de/Planetology (Weber et al. 2018). Our starting material included sanidine from Volkesfeld, Eifel, Germany (ID 73), microcline from Prilep, North Macedonia (ID 151), and albite from Cazadero, California (ID 125). ID 73 sanidine, $\left(\mathrm{Na}_{15} \mathrm{~K}_{85}\right)\left[\mathrm{AlSi}_{3} \mathrm{O}_{8}\right]$, is of gem-stone quality, being transparent. Its $\mathrm{Al}, \mathrm{Si}$ order is low, $2 \mathrm{t}_{1}=0.61$ (Kroll and Knitter 1991). ID 151 microcline, $\left(\mathrm{Na}_{5} \mathrm{~K}_{95}\right)\left[\mathrm{AlSi}_{3} \mathrm{O}_{8}\right]$, is a light greenish powder sample fraction $(100 \mu \mathrm{m}$ to $125 \mu \mathrm{m})$ prepared from the original perthitic microcline (amazonite) from Prilep, which contains some exsolved albite. The $\mathrm{Al}$ content of the $\mathrm{T}_{1} 0$ site is 0.99 (Strob 1983). ID 125 albite has a white color and represents an endmember of the alkali feldspar solid solution in terms of $\mathrm{Ab}$ content $\left(\mathrm{Ab}_{99.9}\right)$ and $\mathrm{Al}, \mathrm{Si}$ order $\left(\mathrm{t}_{1} \mathrm{O}=1.00\right)$ (Wenk and Kroll 1984). These natural samples were treated in different ways as described in section sample treatment.

\section{Sample characterization}

Natural as well as commercially available minerals are often impure. We checked for impurities using light microscopy of thin sections, which also allowed us to distinguish between different compositions and states of order.

To determine the degree of $\mathrm{Al}, \mathrm{Si}$ order, XRD patterns were obtained with a Philips X'Pert powder diffractometer, equipped with a primary Ge monochromator and with a Bruker D8 ADVANCE. For the XRD measurements, some sample material was crushed in an agate mortar to receive a "X-ray fine" grain size (approx. $1 \mu \mathrm{m}$ to $10 \mu \mathrm{m}$ ), controlled by light microscopy. The powder was mixed with Si powder as internal standard to correct the zero shift of the X-ray diffractometers. Rietveld analysis of the XRD patterns were performed with the FULLPROF software (Rodriguez-Carvajal 2005) to refine the lattice parameters. Atomic coordinates and lattice parameters for albite were taken from Wenk and Kroll (1984), for

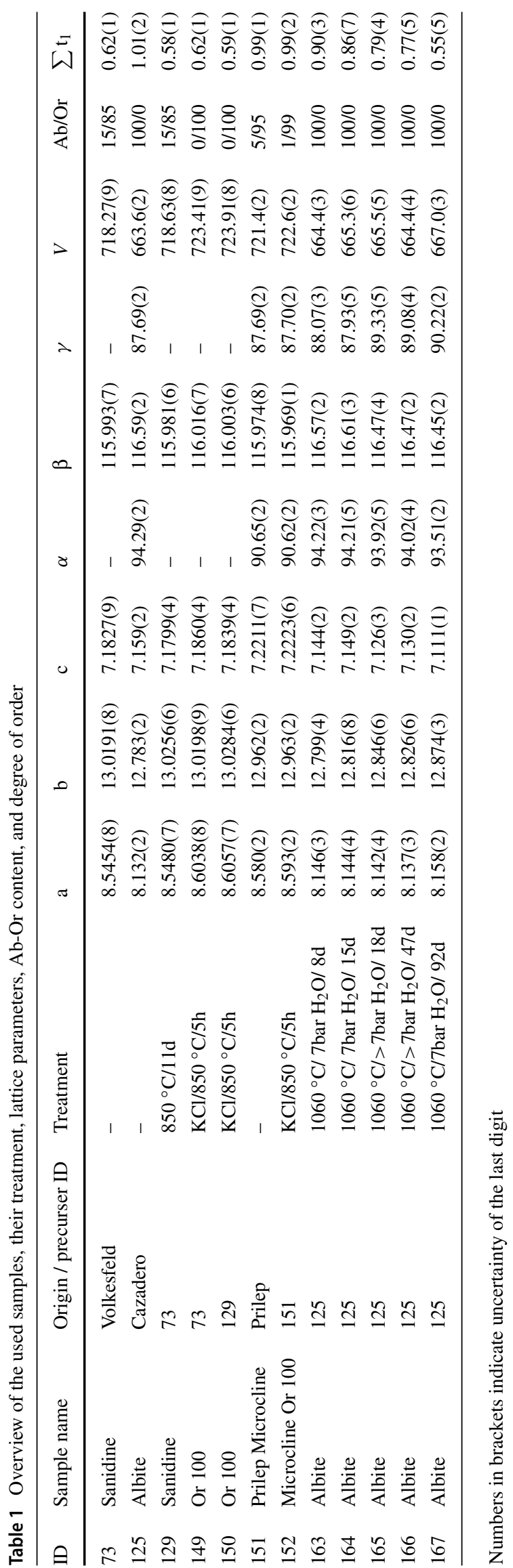


microcline from Strob (1983), and for sanidine from Kroll et al. (1986). Based on the obtained lattice parameters, Al,Si site occupancies were derived from equations given by Kroll and Ribbe (1987) (Table 1).

\section{Sample treatment}

For our investigation we needed alkali feldspars with endmember compositions, which possess a maximum spread of ordering states. Natural feldspars do not fulfill these requirements. Therefore, we performed annealing experiments to vary the state of order as well as alkali exchange experiments to change compositions. Volkesfeld sanidine, ID 73, has been heated at $850{ }^{\circ} \mathrm{C}$ for $11 \mathrm{~d}$ (days), thereby slightly decreasing its state of order. Much larger changes were obtained for the Cazadero low albite. A portion of ID 125 was filled in platinum tubes (ca. $1 \mathrm{~g}$ per tube) and sealed in evacuated silica glass tubes together with gibbsite (=hydrargillite, $\left.\mathrm{Al}(\mathrm{OH})_{3}\right)$. The samples were heated at $1060{ }^{\circ} \mathrm{C}$ to produce increasing states of disorder (see Tab. 1 for details). $\mathrm{H}_{2} \mathrm{O}$ released by gibbsite acts as a flux that promotes disordering. The amount of gibbsite was chosen so that the $\mathrm{H}_{2} \mathrm{O}$ pressure was about 7 bar. The samples were recovered after $8 \mathrm{~d}$ (ID 163), $15 \mathrm{~d}$ (ID 164), $18 \mathrm{~d}$ (ID 165), $47 \mathrm{~d}$ (ID 166) and finally after $92 \mathrm{~d}$ (ID 167). While Cazadero low albite is a pure Na-feldspar endmember, Volkesfeld sanidine and Prilep microcline contain some Ab component. They were thus treated by the alkali exchange method to produce K-feldspar endmembers (Kroll et al. 1986). Charges of ID 73, ID 129 (63 $\mu \mathrm{m}$ to $125 \mu \mathrm{m})$ and ID $151(100 \mu \mathrm{m}$ to $125 \mu \mathrm{m})$ were heated at $850{ }^{\circ} \mathrm{C}$ for $5 \mathrm{~h}$ in an excess of molten $\mathrm{KCl}$ in a covered $\mathrm{Pt}$ crucible in order to exchange $\mathrm{Na}$ ions by $\mathrm{K}$ ions. The weight ratio sample/ $\mathrm{KCl}$ was set at 1:4.5 (ID $73 \rightarrow$ ID 129), 1:70 (ID $129 \rightarrow$ ID 150), and 1:5 (ID $151 \rightarrow$ ID 152). Both small and large weight ratios led to the desired results. After the experiments, the samples were washed with distilled water, filtered and then dried at $50{ }^{\circ} \mathrm{C}$ for several hours. The Or contents of the exchange products were determined from the position of the composition-sensitive $(\overline{2} 01)$ reflection in X-ray powder diagrams (Kroll et al. 1986, their Table 9) resulting in $\mathrm{Or}_{99}$ and $\mathrm{Or}_{100}$, respectively (Table 1).

\section{Infrared and analysis procedure}

For the IR measurements, all samples were crushed in a steel mortar and/or agate mortar and sieved to grain sizes $<25 \mu \mathrm{m}, 25 \mu \mathrm{m}$ to $63 \mu \mathrm{m}, 63 \mu \mathrm{m}$ to $125 \mu \mathrm{m}, 125 \mu \mathrm{m}$ to $250 \mu \mathrm{m}$, and grains greater than $250 \mu \mathrm{m}$. Mid-infrared measurements were performed with a Bruker 70v FTIR spectrometer with a spectral resolution of $4 \mathrm{~cm}^{-1}$ using a grazing angle unit A513. We used a liquid nitrogen cooled MCT (mercury cadmium telluride) detector, and all measurements took place at pressures of $2 \mathrm{hPa}$ at room temperature (ca. $23{ }^{\circ} \mathrm{C}$ ). For the background spectrum we used a commercially available diffuse gold standard $\left(\right.$ INFRAGOLD $\left.{ }^{\mathrm{TM}}\right)$. The powder samples were placed in an aluminum sample holder, $1 \mathrm{~cm}$ in diameter and 1.5 $\mathrm{mm}$ in depth, and flattened with a spatula. Each grain size fraction was measured at two different geometries, with an incident angle (i) of $20^{\circ}$ and emergent angle (e) of $30^{\circ}\left(\mathrm{i} 20^{\circ} \mathrm{e} 30^{\circ}\right)$ and with an incident and emergent angle of $30^{\circ}\left(\mathrm{i} 30^{\circ} \mathrm{e} 30^{\circ}\right.$ ). For each sample and background measurement, 512 single interferogram scans in double sided foreward-backward scan mode were summed up, and the spectrum was calculated through Fourier transformation. In the wavelength region we measured, silicates show characteristic spectral features: (1) The Christiansen Feature $(\mathrm{CF})$, which is a reflectance minimum at which the sample is mostly transparent for the infrared radiation because there is a rapid change of the real part of the refractive index in the sample (Conel 1969). This feature is diagnostic for the mineralogy (Conel 1969). (2) The Reststrahlen Bands (RB), as a result of dominating surface scattering of photons. $\mathrm{RBs}$ arise from the $\mathrm{Si}-\mathrm{O}$ and $\mathrm{Al}-\mathrm{O}$ stretching (e.g., Pieters and Englert 1993; Iiishi et al. 1971). (3) The Transparency Feature (TF) results from increased volume scattering of the infrared radiation and is only visible in samples with small grain sizes $(<25 \mu \mathrm{m})$ (Pieters and Englert 1993).

Because peak fitting is complex (Malcherek et al. 1999), especially in powder reflectance spectra with broad and overlapping peaks, we decided to use the autocorrelation method, which gives us a measure of the peak widths. This method was used successfully to determine the degree of order in cordierite and $\mathrm{Al}, \mathrm{Ge}$ ordering in $\mathrm{Ba}\left[\mathrm{Al}_{2} \mathrm{Ge}_{2} \mathrm{O}_{8}\right]$ feldspar (e.g., Malcherek et al. 1995; Salje et al. 2000). Following this, we analyzed the feldspar infrared spectra not only in terms of band positions but also with autocorrelation of specific band regions. For this we had to slightly modify the method given by Salje et al. (2000) and calculated the following correlations. From the autocorrelation function we used the FWHM (Full Width at Half Maximum) of the complete autocorreleation function for two specific band regions from $8 \mu \mathrm{m}$ to $9 \mu \mathrm{m}$ and from $9 \mu \mathrm{m}$ to $10 \mu \mathrm{m}$, because of the remarkable changes in the spectra in these bands without baseline correction. Gaussian fits to the central part of the autocorrelation function from $7.27 \mu \mathrm{m}$ to $12.11 \mu \mathrm{m}$ were calculated with a constant offset around zero considering our spectral resolution (Offset values for fitting: $-26 \mathrm{~cm}^{-1}$ and $26 \mathrm{~cm}^{-1}$. From this fit to the central part of the autocorrelation function we used the width $\omega$, which corresponds with $k_{2}$ in Salje et al. (2000). 
Fig. 1 a Spectra of all samples with $\mathrm{Ab}_{100}$ with different degree of order and grain sizes between $63 \mu \mathrm{m}$ and $125 \mu \mathrm{m}\left(\mathrm{i} 20^{\circ}, \mathrm{e} 30^{\circ}\right)$. The gray region indicates the measurement range of MERTIS. The black lines indicate a feature shifting with $\sum \mathrm{t}_{1}$ and Or content. The dashed lines indicate the borders of the region for autocorrelation analysis and the associated fit analyzes to determine the degree of order. The dashed-dotted lines indicates the bands for autocorrelation analyzes for the determination of the Or content. b The same as in a but for samples with $\mathrm{Or}_{100}$ to $\mathrm{Or}_{85}$

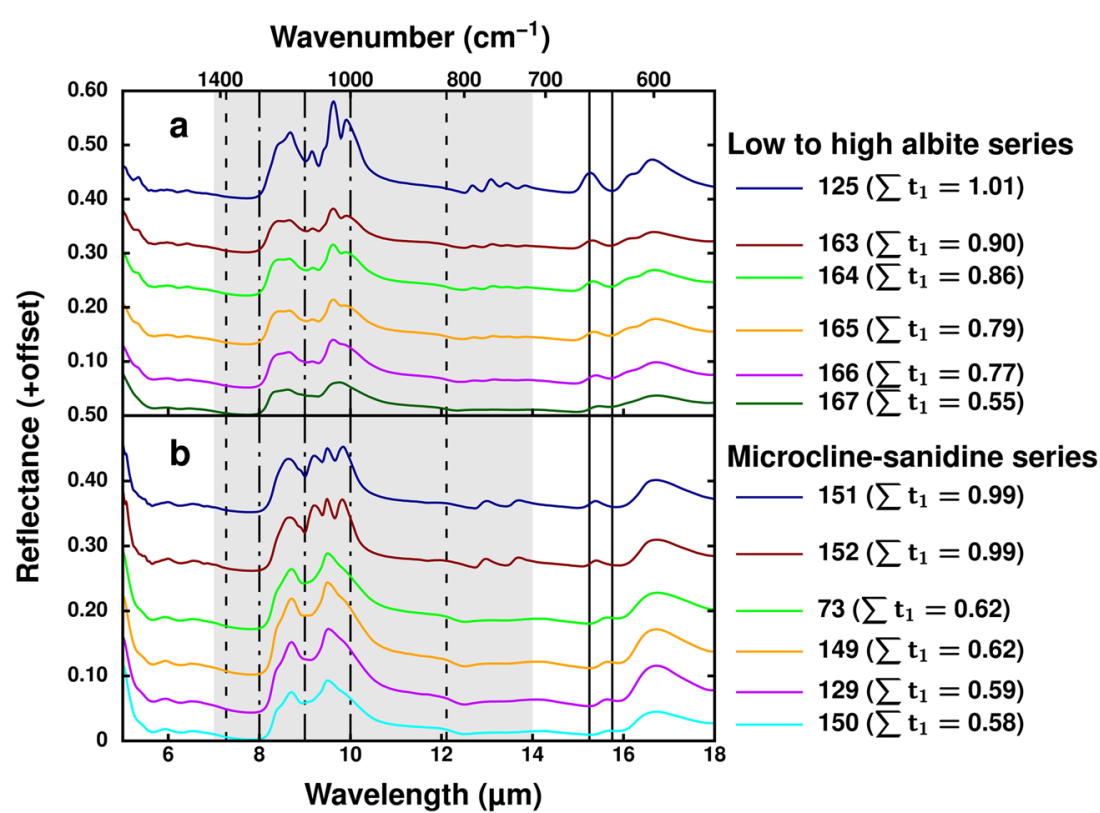

\section{Results}

\section{X-ray diffraction}

Heating of the Volkesfeld sanidine (ID 73) for eleven days at $850{ }^{\circ} \mathrm{C}$ led to further disorder resulting in a final value of $\sum \mathrm{t}_{1}=0.58$ (ID 129). Heating of samples ID 73 and ID 129 in molten $\mathrm{KCl}$ lead to an Or content of $100 \%$ in the samples ID 149 and ID 150. The degree of order remained unchanged. After ion exchange of the Prilep Microcline ID 151 in molten $\mathrm{KCl}$, the produced sample (ID 152) had an Or content of $99 \%$ with no observable $\mathrm{Ab}$ component in the XRD diagram. The calculated degree of order was also unchanged within the range of uncertainty (Table 1).

The degree of order in the low albite sample ID 163 that had been heated for 8 days at $1060{ }^{\circ} \mathrm{C}$ decreased from $\sum \mathrm{t}_{1}=1$ to 0.90 ; after $15 \mathrm{~d}$ it was down to 0.86 (ID 164). In the experiment that lasted $18 \mathrm{~d}$ (ID 165), the silica glass tube was bulging and was possibly broken, most likely because of a too high water vapor pressure. The crystals, however, were not molten. XRD analysis showed two albite populations, $32 \%$ of the original low albite had not yet started to disorder, $68 \%$ were high albite with $\sum \mathrm{t}_{1}=$ 0.69 . An average value of $\sum t_{1}=0.79$ was assigned to
Fig. 2 a Spectra of all samples with $\mathrm{Ab}_{100}$ with different degree of order and grain sizes smaller $25 \mu \mathrm{m}\left(\mathrm{i} 20^{\circ}, \mathrm{e} 30^{\circ}\right)$. The gray region indicates the measurement range of MERTIS. The black lines indicate a feature shifting with $\sum \mathrm{t}_{1}$ and Or content. The dashed lines indicate the borders of the region for autocorrelation analysis and the associated fit analyzes to determine the degree of order. The dashed-dotted lines indicates the bands for autocorrelation analyzes for the determination of the Or content. b The same as in a but for samples with Or $_{100}$ to Or $_{85}$

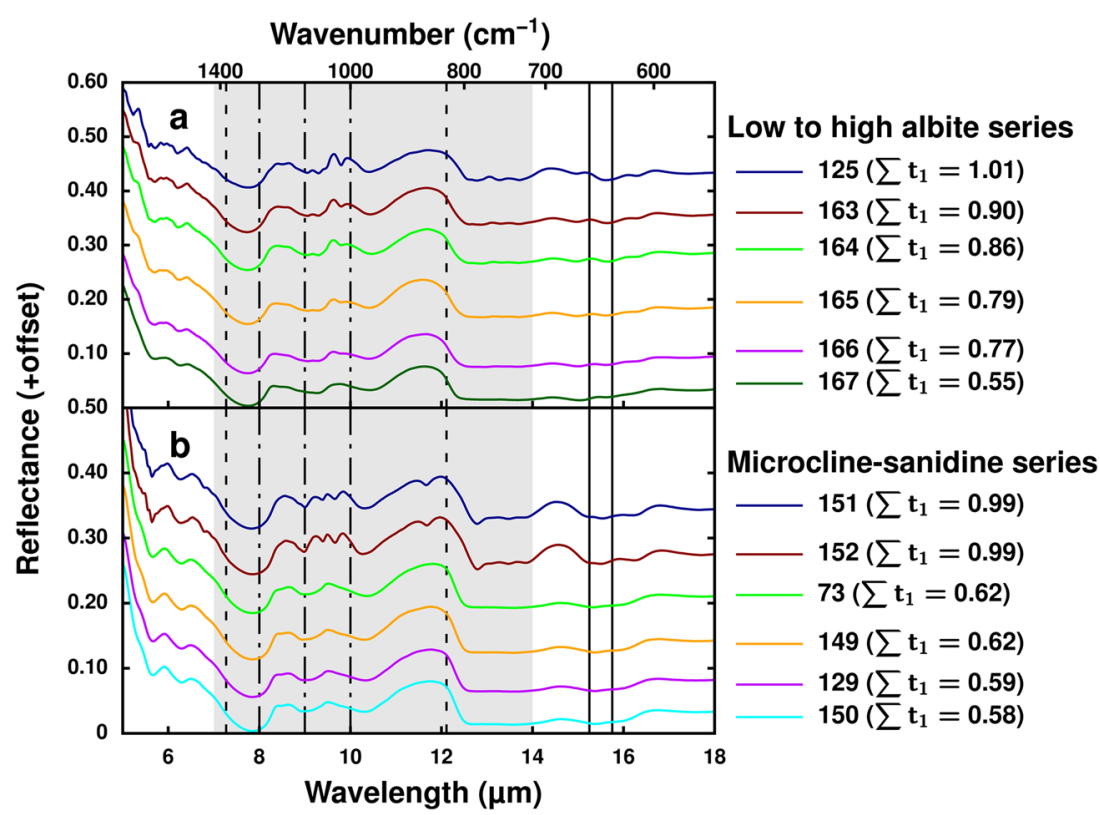


the sample. The silica glass tube of sample ID 166 also strongly bulged but did not break and for this sample, the degree of order was determined from XRD refinment to $\sum \mathrm{t}_{1}=0.77$. For sample ID 167, after opening the tube a small hole near the weld seam was noticed. At this position the tube wall was probably thinner because of welding and therefore a hole could form due to the water vapor pressure. The calculation of the degree of order gave a highly disordered $\sum \mathrm{t}_{1}=0.55$. All samples, their precursor material, treatment, refined XRD data, Ab-Or-content, as well as degree of $\mathrm{Al}, \mathrm{Si}$ order are listed in Table 1 (compare section results).

\section{Infrared}

Our main goal was to investigate the spectral range between $7 \mu \mathrm{m}$ and $14 \mu \mathrm{m}$ (marked by a gray background in Figs. 1 and $2 \approx 1429 \mathrm{~cm}^{-1}$ to $714 \mathrm{~cm}^{-1}$ ), which corresponds to the measurement range of the MERTIS instrument. The overall reflectance of our samples decreases with decreasing particle size because surface scattering is decreased compared to volume scattering. The autocorrelation function was used for the analysis of this spectral range (ranges of autocorrelation calculations: $8 \mu \mathrm{m}$ to $9 \mu \mathrm{m}\left(1250 \mathrm{~cm}^{-1}\right.$ to $\left.1111 \mathrm{~cm}^{-1}\right), 9 \mu \mathrm{m}$ to $10 \mu \mathrm{m}$ $\left(1111 \mathrm{~cm}^{-1}\right.$ to $\left.1000 \mathrm{~cm}^{-1}\right)$, and $7.27 \mu \mathrm{m}$ to $12.11 \mu \mathrm{m}$ $\left(825 \mathrm{~cm}^{-1}\right.$ to $\left.1376 \mathrm{~cm}^{-1}\right)$.

Figure 1 shows the spectra of samples with a grain size of $63 \mu \mathrm{m}$ to $125 \mu \mathrm{m}$, measured at $\mathrm{i} 20^{\circ}$ and $\mathrm{e} 30^{\circ}$ for samples with compositions $\mathrm{Ab}_{100}$ (Fig. 1a) and $\mathrm{Or}_{100}$ to $\mathrm{Or}_{85}$ (Fig. 1 b). The spectra change with the degree of $\mathrm{Al}, \mathrm{Si}$ order. $\mathrm{RB}$ peaks, which are related to $\mathrm{Si}-\mathrm{O}$ and $\mathrm{Al}-\mathrm{O}$ stretching (Iiishi et al. 1971), broaden and disappear with increasing disorder. In the ordered species (ID 151, 152, 125), four clear bands and one to two shoulders can be distinguished between $8 \mu \mathrm{m}\left(1250 \mathrm{~cm}^{-1}\right)$ and $10.5 \mu \mathrm{m}\left(952 \mathrm{~cm}^{-1}\right)$ in the region of the RBs. In contrast, the spectra of disordered species show only two or three broad peaks and two or three shoulders. Spectral differences resulting from the varying Or content in the disordered samples (ID 73, 129, 149, 150) are only minor. The absolute intensities of the RB peaks change with the degree of order as well. There are no observable RB shifts resulting from $\mathrm{Al}, \mathrm{Si}$ distribution changes. The mean wavelength of the CFs is ca. $7.83 \mu \mathrm{m}\left(1277 \mathrm{~cm}^{-1}\right)$ for the Or-rich samples (ID 73, 129, 149, 150, 151, 152) compared to $7.72 \mu \mathrm{m}\left(1295 \mathrm{~cm}^{-1}\right)$ for the $\mathrm{Ab}_{100}$ samples (ID 125 , $163,164,165,166,167)$. As an effect of small grain sizes, spectral contrast and overall reflectance are reduced (Fig. 2). Thus, the peaks in the spectral region of the RB in samples with a high $\mathrm{Al}, \mathrm{Si}$ order are weak but still distinguishable. In the spectra of the more disordered species (ID 73, 129, $149,150,165,166,167)$, the small grain sizes also led to a decrease of the RB bands, so that the spectra are difficult to distinguish. In addition, the TF is clearly visible in the spectra as a large broad peak between $11 \mu \mathrm{m}$ and $12 \mu \mathrm{m}$ $\left(909 \mathrm{~cm}^{-1}\right.$ and $833 \mathrm{~cm}^{-1}$ ).

\section{Discussion}

\section{General remarks}

In the following, we discuss the infrared powder reflectance spectra results in terms of peak shift and the autocorrelation
Fig. 3 a Band position of the feature marked in Fig. 1 for grain sizes between $63 \mu \mathrm{m}$ and $125 \mu \mathrm{m}$. Dashed-dotted line $\mathrm{Or}_{100}$ fit; dotted line $\mathrm{Ab}_{100}$ fit. b Same as a for figure but for grain sizes smaller $25 \mu \mathrm{m}$

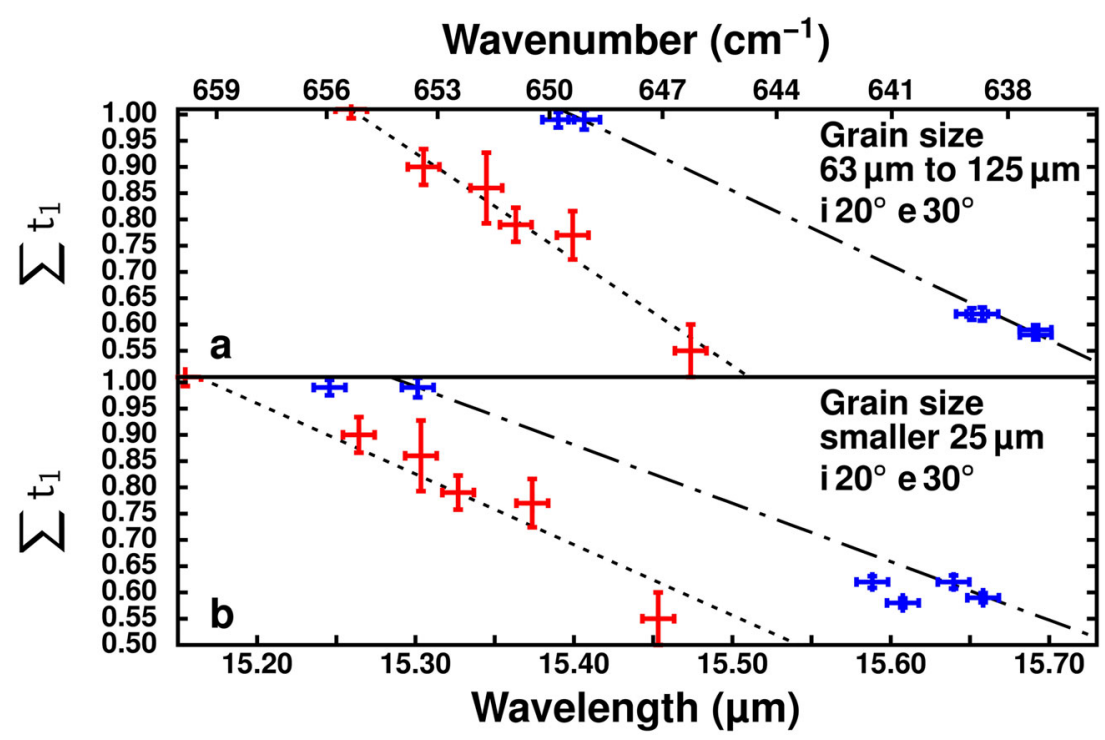

Fit $\mathrm{Ab}_{100} \ldots \ldots$

Fit Or $_{100}-\cdots$ 
analyzes for the three different grain size fractions. In addition, we debate implications that arise for remote sensing.

IR absorption spectra show decreasing band intensities, increasing linewidths, and shifts of bands with decreasing $\mathrm{Al}$,Si order (e.g., Zhang et al. 1997). Our powder reflectance spectra exhibit the same changes. Zhang et al. (1997) correlated peak positions and linewidths of absorption spectra above $16.6 \mu \mathrm{m}$ (below $600 \mathrm{~cm}^{-1}$ ) and in the far infrared around $33 \mu \mathrm{m}\left(300 \mathrm{~cm}^{-1}\right)$ with Or content and degree of order of alkali feldspars. In contrast, our study focused on the mid-IR, especially the wavelength region from $7 \mu \mathrm{m}$ to $14 \mu \mathrm{m}\left(1429 \mu \mathrm{m}\right.$ to $\left.714 \mathrm{~cm}^{-1}\right)$, which is the measurement range of the MERTIS experiment (Hiesinger et al. 2010; H. Hiesinger and co-workers, in preparation).

Following the classification of Iiishi et al. (1971), the IR bands between $8.6 \mu \mathrm{m}\left(1162 \mathrm{~cm}^{-1}\right)$ and $17.2 \mu \mathrm{m}$ $\left(580 \mathrm{~cm}^{-1}\right)$ should only depend on stretching and bending of the bonds between $\mathrm{Si}$ or $\mathrm{Al}$ and O-ions. In contrast, we found in our analysis, that this wavelength region is also affected by the Or-content. This is probably associated with the change of the bond length $<\mathrm{T}-\mathrm{O}>$ in the alkali feldspar crystal structure due to the Or-content (Ribbe 1983).

\section{Feature shift analysis}

In Fig. 3, the position of the maximum of the spectral feature, denoted as $15.48 \mu \mathrm{m}\left(646 \mathrm{~cm}^{-1}\right)$ feature thereafter, that is bounded by two black lines in Figs. 1 and 2 is plotted versus the degree of order, $\sum t_{1}$. The marked feature shifts from $15.26 \mu \mathrm{m}\left(655 \mathrm{~cm}^{-1}\right)$ in pure low albite to $15.40 \mu \mathrm{m}\left(649 \mathrm{~cm}^{-1}\right)$ in disordered high albite. These results are in agreement with the peak shifts in absorption spectra reported by Zhang et al. (1996) for low albite but for the high albite sample it is shifted around $\Delta=0.12 \mu \mathrm{m}$ towards shorter wavelengths (higher wavenumbers; $\Delta=$ $5 \mathrm{~cm}^{-1}$ ). In microcline with Or $_{100}$ the feature is at $15.41 \mu \mathrm{m}$ $\left(649 \mathrm{~cm}^{-1}\right)$ and shifts to $15.69 \mu \mathrm{m}\left(637 \mathrm{~cm}^{-1}\right)$ in highly disordered sanidine with $\mathrm{Or}_{100}$ (Fig. 3). Zhang et al. (1996) reported an absorption feature in microcline also at around $15.43 \mu \mathrm{m}\left(648 \mathrm{~cm}^{-1}\right)$ and for highly disordered sanidine with $\mathrm{Or}_{100}$ at around $15.67 \mu \mathrm{m}\left(638 \mathrm{~cm}^{-1}\right)$, which is in agreement with our reflectance data. These discussed features in the spectral range around $15.48 \mu \mathrm{m}\left(646 \mathrm{~cm}^{-1}\right)$ should be originating from bending of $\mathrm{O}-\mathrm{Si}(\mathrm{Al})-\mathrm{O}$ bonds (Zhang et al. 1996). The intensity of this bond depends on the degree of order (Iiishi et al. 1971). Our results confirm these findings as seen in Fig. 3a. In addition, the Or-Ab content also affects shape and position of the analyzed feature in reflectance spectra. Therefore, we fitted the wavelength of the $15.48 \mu \mathrm{m}\left(646 \mathrm{~cm}^{-1}\right)$ feature to the degree of $\mathrm{Al}, \mathrm{Si}$ order of the samples with $\mathrm{Or}_{100}$ and $\mathrm{Ab}_{100}$, respectively. The $15.48 \mu \mathrm{m}\left(646 \mathrm{~cm}^{-1}\right)$ feature in the spectra of samples with grain sizes smaller than $25 \mu \mathrm{m}$ (Fig. 3b) is not as well resolved as in the spectra for the larger grain sizes (Fig. 3a). In the microcline-sanidine series (ID 73, 129, 149, 150, 151, 152) the $15.28 \mu \mathrm{m}\left(646 \mathrm{~cm}^{-1}\right)$ feature is only visible as a shoulder. In these cases, fitting of the spectral region of interest was done with a function of the form $R(\lambda)=a \cdot(b-\lambda)^{3}+d \cdot \lambda+c(R$ reflectance, $\lambda$ wavelength in $\mu \mathrm{m}$ ). The variation of the band position with $\sum t_{1}$ is about the same for both grain size fractions (Fig. 3). The slopes and intercepts with the y-axis of the straight lines are, however, affected by the grain size, which highlights the need of powder reflectance spectra for remote sensing (Table 2). The $15.28 \mu \mathrm{m}\left(646 \mathrm{~cm}^{-1}\right)$ feature shifts slightly (mean deviation $\Delta_{125-25} \approx 0.06 \mu \mathrm{m}$ ) to shorter

Table 2 Functions of the different fits calculated with the software gnuplot v.5.2

\begin{tabular}{lll}
\hline Correlation & Figure & Function \\
\hline Band position $\mathrm{Or}_{100}$ samples $-\sum \mathrm{t}_{1} 63 \mu \mathrm{m}$ to $125 \mu \mathrm{m}$ & $3 \mathrm{a}$ & $-1.42 \cdot \lambda+22.91$ \\
Band position $\mathrm{Ab}_{100}$ samples $-\sum \mathrm{t}_{1} 63 \mu \mathrm{m}$ to $125 \mu \mathrm{m}$ & $3 \mathrm{a}$ & $-2.02 \cdot \lambda+31.90$ \\
Band position $\mathrm{Or}_{100}$ samples $-\sum \mathrm{t}_{1}<25 \mu \mathrm{m}$ & $3 \mathrm{~b}$ & $-1.11 \cdot \lambda+18.00$ \\
Band position $\mathrm{Ab}_{100}$ samples $-\sum \mathrm{t}_{1}<25 \mu \mathrm{m}$ & $3 \mathrm{~b}$ & $-1.34 \cdot \lambda+21.38$ \\
Ratio of FWHM of autocorrelation functions $(\Psi)-$ Or-content $63 \mu \mathrm{m}$ to $125 \mu \mathrm{m}$ & $5 \mathrm{a}$ & $-321 \cdot \Psi+403$ \\
Ratio of FWHM of autocorrelation functions $(\Psi)-$ Or-content $25 \mu \mathrm{m}$ to $63 \mu \mathrm{m}$ & $5 \mathrm{~b}$ & $-360 \cdot \Psi+454$ \\
Ratio of $\mathrm{FWHM}$ of autocorrelation functions $(\Psi)-$ Or-content $<25 \mu \mathrm{m}$ & $5 \mathrm{c}$ & $-428 \cdot \Psi+568$ \\
$\omega_{\text {Gauss }}-\sum \mathrm{t}_{1}$ all samples $63 \mu \mathrm{m}$ to $125 \mu \mathrm{m}$ & $6 \mathrm{a}$ & $-0.0005 \cdot(26-\omega)^{2}+1.02$ \\
$\omega_{\text {Gauss }}-\sum \mathrm{t}_{1} \mathrm{Ab}_{100} 25 \mu \mathrm{m}$ to $63 \mu \mathrm{m}$ & $6 \mathrm{~b}$ & $-0.032 \cdot \omega+1.9$ \\
$\omega_{\text {Gauss }}-\sum \mathrm{t}_{1} \mathrm{Ab}_{100} 25 \mu \mathrm{m}$ to $63 \mu \mathrm{m}$ & $6 \mathrm{~b}$ & $-0.016 \cdot \omega+1.5$ \\
$\omega_{\text {Gauss }}-\sum \mathrm{t}_{1} \mathrm{Or}_{100}<25 \mu \mathrm{m}$ & $6 \mathrm{c}$ & $-0.12 \cdot \omega+4.3$ \\
$\omega_{\text {Gauss }}-\sum \mathrm{t}_{1} \mathrm{Ab}_{100}<25 \mu \mathrm{m}$ & $6 \mathrm{c}$ & $-0.06 \cdot \omega+2.8$ \\
\hline
\end{tabular}

$\lambda$ in $\mu \mathrm{m}, \Psi$ is dimensionless, $\omega$ in $\mathrm{cm}^{-1}$ 
Fig. 4 Typical autocorrelation function (Auto.corr. is the value of the autocorrelation function) with marked FWHM and fit to the central peak between -26 $\mathrm{cm}^{-1}$ and $26 \mathrm{~cm}^{-1}$ (inset with $\omega$ of the Gaussian fit): ID 125 albite, spectral range $7.27 \mu \mathrm{m}$ to $12.11 \mu \mathrm{m}$

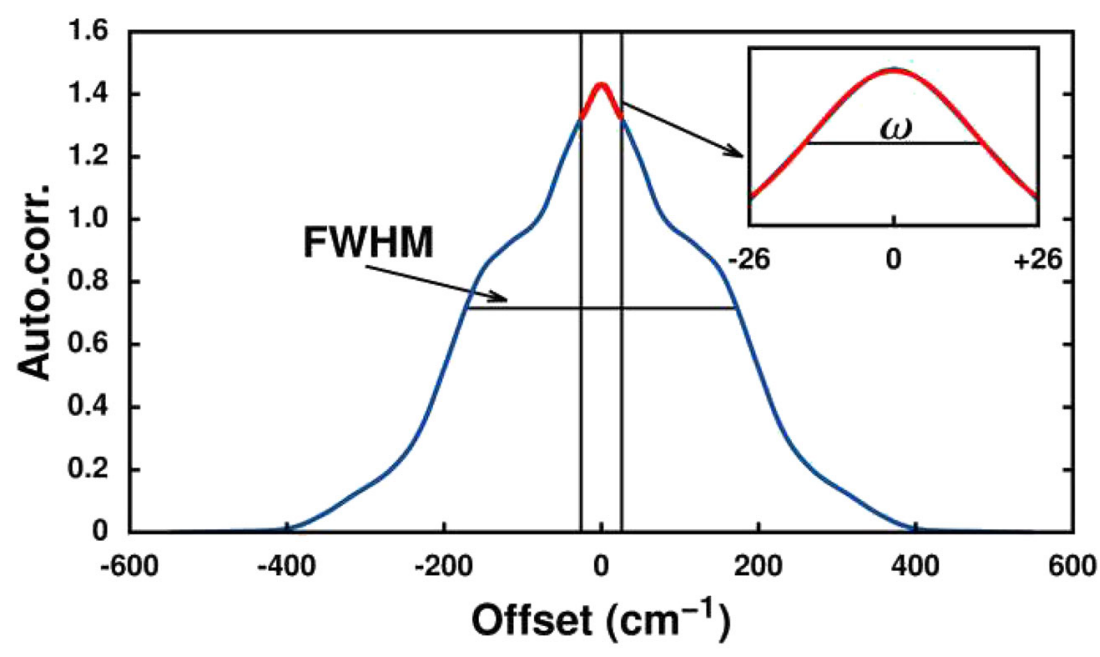

Autocorrelation function for albite, ID $125,7.27 \mu \mathrm{m}$ to $12.11 \mu \mathrm{m}$ Gaussian fit to central part

wavelengths in the sample fraction with smaller grain sizes. This deviation is $0.01 \mu \mathrm{m}$ larger than our estimated upper bound of the uncertainty of the feature wavelength of $0.05 \mu \mathrm{m}$. In particular, two microcline samples (ID 151, $152)$ and the albite sample (ID 125) show larger deviations $\left(\Delta_{125-25, \mathrm{MICRO}, \mathrm{ALB}} \approx 0.12 \mu \mathrm{m}\right)$ from the large to the small grain sizes. For all other samples, the mean deviation is at the upper bound of uncertainty; therefore, the grain sizedependent shift of the feature could be neglected. Based on our study we conclude, that with the feature shift analysis of the $15.28 \mu \mathrm{m}\left(646 \mathrm{~cm}^{-1}\right)$ feature, the degree of order of an alkali feldspar can be estimated if the chemical composition is known.

\section{Autocorrelation analysis}

The calculations of the autocorrelation analyses were related to the degree of order and the Or content. Figure 4 shows a typical autocorrelation function. We tested several different ways of combining autocorrelation analyses (linear, polynomial, and ratio correlations) and degree of order as well as Or content. Ratios of different spectral regions are a common way in multi- or hyperspectral data analysis to identify distinct chemical compositions (e.g., Vincent and Thomson 1972; Kirland et al. 2002). In Fig. 5, the ratio FWHM of the autocorrelation function of the spectral range from $8 \mu \mathrm{m}$ to $9 \mu \mathrm{m}\left(1250 \mu \mathrm{m}\right.$ to $\left.1111 \mathrm{~cm}^{-1}\right)$
Fig. 5 Correlation between Or content and $\Psi$, which is defined as the ratio of the FWHM of the autocorrelation function of the spectral range from $8 \mu \mathrm{m}$ to $9 \mu \mathrm{m}$ to that of the spectral range from $9 \mu \mathrm{m}$ to $10 \mu \mathrm{m}$ (see dashed-dotted lines in Figs. 2 and 3) a Grain sizes of $63 \mu \mathrm{m}$ to $125 \mu \mathrm{m}$; b Grain sizes from $25 \mu \mathrm{m}$ to $63 \mu \mathrm{m}$, and $\mathbf{c}$ Grain sizes smaller than $25 \mu \mathrm{m}$. The yellow data point is sample ID 12 with $\mathrm{Or}_{62}$. Although it supports the linear trend between the endmembers it was not used for the fit because of contamination with quartz

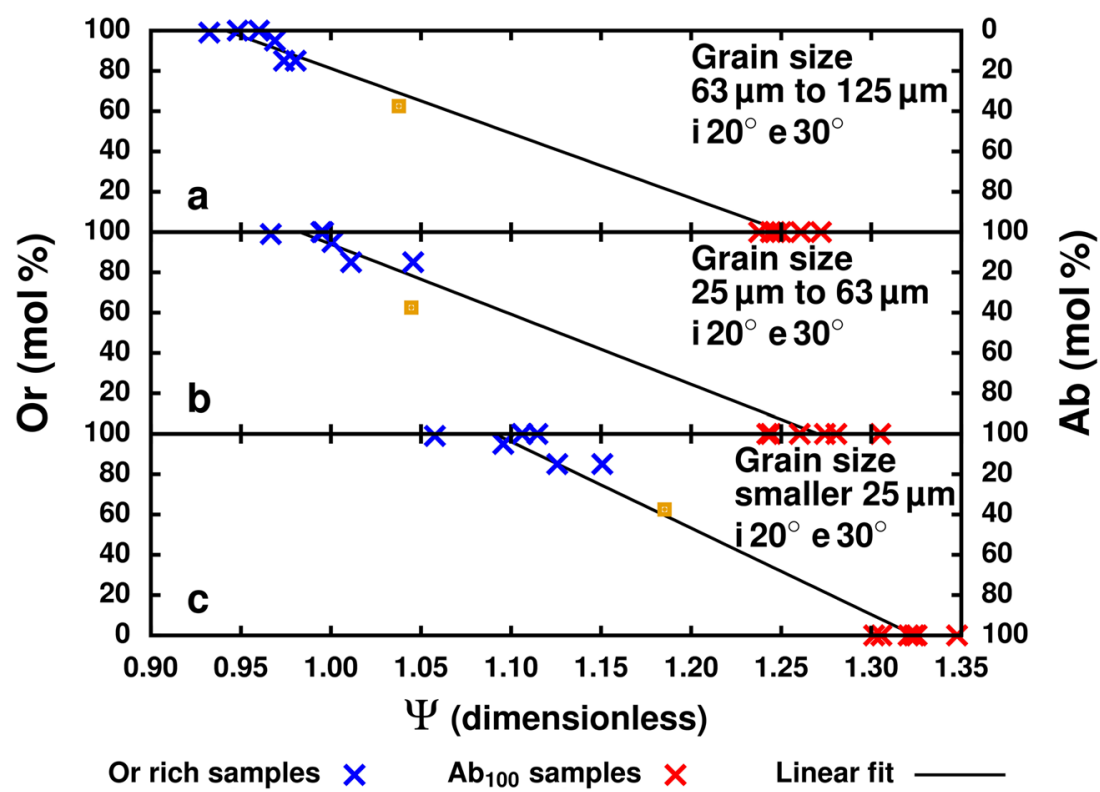


to that of the spectral range from $9 \mu \mathrm{m}$ to $10 \mu \mathrm{m}(1111 \mu \mathrm{m}$ to $1000 \mathrm{~cm}^{-1}$ ) (denoted as $\Psi$ thereafter) is plotted against the Or content for all analyzed samples and grain size fractions. Samples with smaller Or contents have a larger $\Psi$ value than Or-rich samples.

One measured sample with an intermediate chemical composition between $\mathrm{Or}$ and $\mathrm{Ab}\left(\mathrm{Or}_{62}\right)$ suggest a linear relationship of $\Psi$ value and Or content (yellow data point in Fig. 5). However, because of some accessory minerals contained in the sample, it was not suitable for exact spectral analysis. To prevent uncertainties resulting of this contamination we fitted our data with a linear function, without using of the data of the sample with intermediate composition. The slope of the fitted straight line and its intercept with the y-axis increase with decreasing grain sizes, but the overall behavior is the same for all fractions (Table 2). The respective fit functions are Or $(\mathrm{mol} \%)=$ $-321 \cdot \Psi+403$ for samples with grain sizes between $63 \mu \mathrm{m}$ and $125 \mu \mathrm{m}$, Or $(\mathrm{mol} \%)=-360 \cdot \Psi+454$ for samples with grain sizes between $25 \mu \mathrm{m}$ and $36 \mu \mathrm{m}$, and Or $(\mathrm{mol} \%)=$ $-428 \cdot \Psi+568$ for the smallest grain size fraction.

In Fig. 6, the width $\omega=F W H M / \sqrt{\ln 4}$ of a Gaussian fit (note: this FWHM is from the Gaussian fit and therefore something different as the FWHM from above) to the central peak from $-26 \mathrm{~cm}^{-1}$ to $26 \mathrm{~cm}^{-1}$ on the $\mathrm{x}$-coordinate of the autocorrelation function of the spectral band region from $7.27 \mu \mathrm{m}$ to $12.11 \mu \mathrm{m}$ (1376 $\mu \mathrm{m}$ to $\left.826 \mathrm{~cm}^{-1}\right)$ is plotted versus the degree of order. The black line in Fig. 6a is a quadratic fit to all the samples with a grain size ranging from $63 \mu \mathrm{m}$ to $125 \mu \mathrm{m}$. The fit function to the dependence of the width $\omega$ of the Gaussian fit curve on $\sum \mathrm{t}_{1}$ is given by $\sum \mathrm{t}_{1}=-0.0005 \cdot(26-\omega)^{2}+1.02$ (Fig. 6a). In Fig. 6b and c, the results for the grain size fractions from $25 \mu \mathrm{m}$ to $63 \mu \mathrm{m}$ and smaller than $25 \mu \mathrm{m}$ are plotted. The analyses of the smaller grain size fractions led to a split in the correlation of $\omega$ and and degree of order for Or-rich samples and Ab-rich samples $\left(\sum \mathrm{t}_{1} \mathrm{Or}_{100}=-0.032 \cdot \omega+1.9\right.$ and $\sum \mathrm{t}_{1} \mathrm{Ab}_{100}=-0.016 \cdot \omega+1.5$ for grain sizes from $25 \mu \mathrm{m}$ to $63 \mu \mathrm{m}$ and $\sum \mathrm{t}_{1} \mathrm{Or}_{100}=-0.12 \cdot \omega+4.3$ and $\sum \mathrm{t}_{1} \mathrm{Ab}_{100}=$ $-0.06 \cdot \omega+2.8$ for the smallest grain size fraction). This implies that the grain size distribution has a large effect on the form of the autocorrelation function in the regions of the RB (Table 2). This is probably an effect of the reduced spectral contrast in combination with decreasing reflectance in spectra of samples with smaller grain sizes compared to those with larger grain sizes. The combination of the effects leads to a reduced FWHM of the peaks which is visible through the calculation of the autocorrelation function.

Iiishi et al. (1971) stated that the mid-IR spectral region of alkali feldspars is unaffected by alkali ions and only affected by the degree of order. In contrast, with the autocorrelation analysis we can distinguish not only the degree of order within infrared reflectance spectra between $7 \mu \mathrm{m}$ and $14 \mu \mathrm{m}$ but also the Or content. Nevertheless, the reflectance spectral behavior is more complex, because the analyzed grain size fractions have an influence on the RBs, which in turn have an influence on the autocorrelation function. Therefore, knowing the grain sizes of the samples is necessary for accurate determinations of Or content and degree of order from the spectra. Best results were obtained from samples with a grain size between $63 \mu \mathrm{m}$ to $125 \mu \mathrm{m}$.

\section{Conclusions}

We investigated reflectance mid-IR powder spectra of endmember alkali feldspars with respect to their Ab-Or content and their $\mathrm{Al}$,Si distribution which were derived from
Fig. 6 Correlation between $\omega$ of Gaussian fit to the central part of the autocorrelation function of the wavelength region from $7.27 \mu \mathrm{m}$ to $12.105 \mu \mathrm{m}$ (see dashed lines in Figs. 2 and 3) and the degree of order $\left(\sum \mathrm{t}_{1}\right)$. a Grain size range from $63 \mu \mathrm{m}$ to $125 \mu \mathrm{m}$. The black line is a quadratic fit to all samples. b Grain size range from $25 \mu \mathrm{m}$ to $63 \mu \mathrm{m}$. Dashed-dotted line $\mathrm{Or}_{100}$ fit; Dashed line $A b_{100}$ fit, and $\mathbf{c}$ Same as b but with grain size smaller than $25 \mu \mathrm{m}$

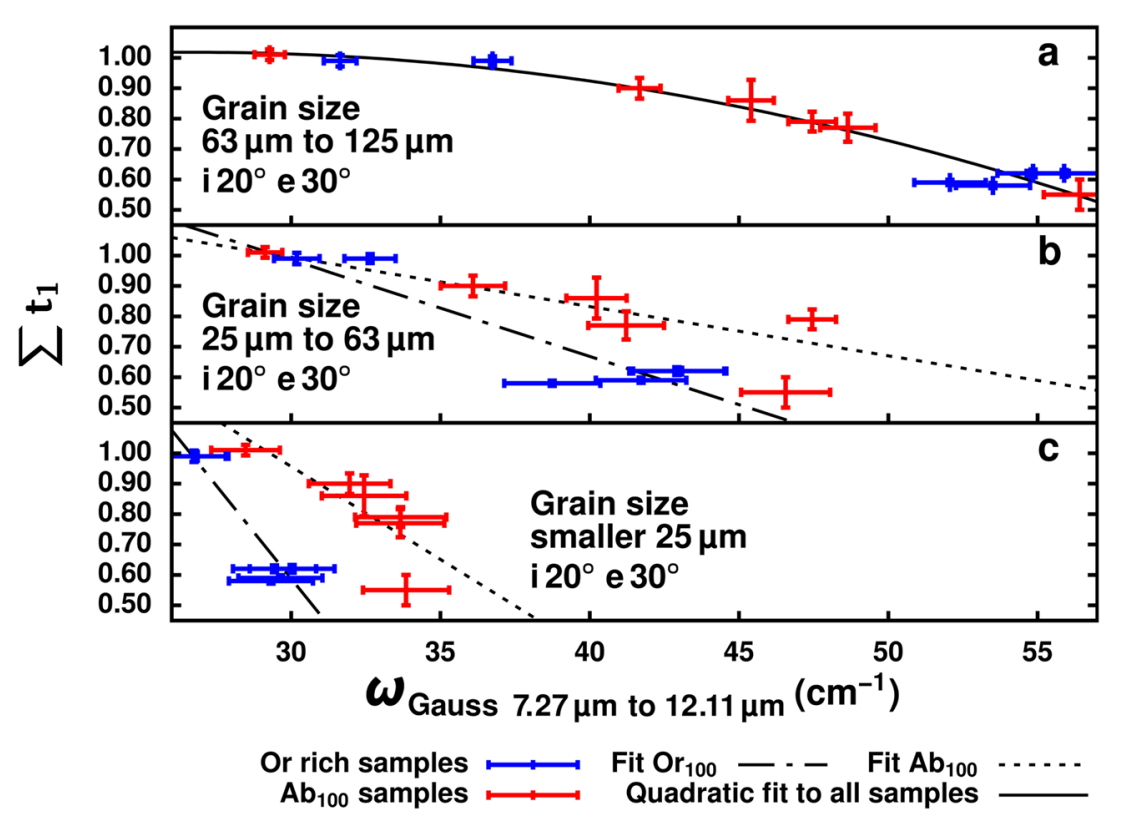


XRD analysis. The results of this study showed that the $\mathrm{Al}, \mathrm{Si}$ degree of order as well as the Or content can be determined by reflectance spectroscopy. Thus, these results are important and applicable for future space missions carrying TIR spectrometers.

Mid-infrared spectra of alkali feldspars are strongly affected by the distribution of $\mathrm{Al}$ and $\mathrm{Si}$ on the nonequivalent tetrahedral sites of the frame-work structure and are less affected by the amount of $\mathrm{K}$ and $\mathrm{Na}$. Previous work showed that the positions of specific absorption bands are related to the Al,Si distribution (e.g., Martin 1970). On the basis of our study, we demonstrate that a specific feature found in all of our investigated spectra around $15.48 \mu \mathrm{m}\left(646 \mathrm{~cm}^{-1}\right)$, which is in the same spectral region as investigated by Martin (1970), is a measure of the state of order. This feature shifts from $15.26 \mu \mathrm{m}$ $\left(655 \mathrm{~cm}^{-1}\right)$ in pure low albite to $15.40 \mu \mathrm{m}\left(649 \mathrm{~cm}^{-1}\right)$ in disordered high albite and from $15.41 \mu \mathrm{m}\left(649 \mathrm{~cm}^{-1}\right)$ in microcline to $15.69 \mu \mathrm{m}\left(637 \mathrm{~cm}^{-1}\right)$ in highly disordered sanidine (Fig. 3). As different means to investigate the degree of order, Malcherek et al. (1995) introduced the autocorrelation analysis of absorption spectra. In contrast to the feature shift analysis discussed above, the autocorrelation analysis, which provides insights into the chemical composition as well as the degree of order, can be applied to the measurement range of MERTIS. We used the autocorrelation analysis on reflectance spectra for different spectral regions. The ratio of FWHM of the autocorrelation function of $8 \mu \mathrm{m}$ to $9 \mu \mathrm{m}\left(1250 \mu \mathrm{m}\right.$ to $\left.1111 \mathrm{~cm}^{-1}\right)$ to the autocorrelation function of $9 \mu \mathrm{m}$ to $10 \mu \mathrm{m}(1111 \mu \mathrm{m}$ to $1000 \mathrm{~cm}^{-1}$ ), called $\Psi$, is linearly dependent on the Or content (Fig. 5). Iiishi et al. (1971) predicted that the alkali ions do not affect the region of the RB in absorption spectra of alkali feldspar. With our approach it is possible to determine the Or content of (pure) alkali feldspars from their reflectance spectra. Salje et al. (2000) suggested autocorrelation of the absorption spectra from $12.11 \mu \mathrm{m}$ to $7.27 \mu \mathrm{m}\left(825 \mathrm{~cm}^{-1}\right.$ to $\left.1376 \mathrm{~cm}^{-1}\right)$ for cordierite and fitting of the central peak of the autocorrelation function with a Gaussian curve to investigate the degree of order. We used the same approach to analyze our powder reflectance spectra because MERTIS measures in the same spectral range and we are also observing spectral changes in these wavelength region. For samples with grain sizes between $63 \mu \mathrm{m}$ and $125 \mu \mathrm{m}$ the correlation of $\sum \mathrm{t}_{1}$ and the width $\omega$ of a Gaussian fit to the central part of the autocorrelation function is independent of the Or-content of the samples and thus allows to identify the degree of order without previous determination of the chemical composition. For samples with a grain size below $63 \mu \mathrm{m}$, however, the relation between $\omega$ and $\sum t_{1}$ becomes dependent on the Or content.
Depending on the spectral deconvolution of data returned from MERTIS, it will be possible not only to determine the degree of order of an alkali feldspar, but also its chemical composition. The data gained in this study as well as the calculated correlations are the basis for further investigations of the feldspar system, especially for remote sensing of other planetary surfaces. Further work on the alkali feldspar system will include samples with intermediate chemical compositions plus mechanical mixtures with the same bulk composition.

Acknowledgements We are grateful to Stephan Klemme and Christian Rengli for their help and permission to use their laboratory, to Ludger Buxtrup for technical support with the furnaces, to Peter Schmid-Beuermann for help with XRD at Institut für Mineralogie, and to Uta Rodehorst for advice and the possibility of using the laboratory at Münster Electrochemical Energy Technology. Constructive comments by Charles Geiger, an anonymous reviewer and handling editor Anton Beran are gratefully acknowledged. This work is partly supported by Deutsches Zentrum für Luft- und Raumfahrt funding 50 QW 1701 in the framework of the Bepi-Colombo mission.

Funding information Open Access funding provided by Projekt DEAL.

\section{Compliance with Ethical Standards}

Conflict of interests The authors declare that they have no conflict of interest.

Open Access This article is licensed under a Creative Commons Attribution 4.0 International License, which permits use, sharing, adaptation, distribution and reproduction in any medium or format, as long as you give appropriate credit to the original author(s) and the source, provide a link to the Creative Commons licence, and indicate if changes were made. The images or other third party material in this article are included in the article's Creative Commons licence, unless indicated otherwise in a credit line to the material. If material is not included in the article's Creative Commons licence and your intended use is not permitted by statutory regulation or exceeds the permitted use, you will need to obtain permission directly from the copyright holder. To view a copy of this licence, visit http://creativecommons. org/licenses/by/4.0/.

\section{References}

Conel JE (1969) Infrared emissivities of silicates: Experimental results and a cloudy atmosphere model of spectral emission from condensed particulate mediums. J Geophys Res 74:1614-1634. https://doi.org/10.1029/JB074i006p01614

Evans LG, Peplowski PN, Rhodes EA, Lawrence DJ, McCoy TJ, Nittler LR, Solomon SC, Sprague AL, Stockstill-Cahill KR, Starr RD, Weider SZ, Boynton WV, Hamara DK, Goldsten JO (2012) Major-element abundances on the surface of Mercury: Results from the MESSENGER gamma-ray spectrometer. J Geophys Res-Planet 117:E00L07. https://doi.org/10.1029/2012JE004178 
Hafner S, Laves F (1957) Ordnung/Unordnung und Ultrarotabsorption II. Variation der Lage und Intensität einiger Absorptionen von Feldspäten. Zur Struktur von Orthoklas und Adular. Z Kristallogr 109:204-225. https://doi.org/10.1524/zkri.1957. 109.1-6.204

Hecker C, van der Mijde M, van der Meer FD (2010) Thermal infrared spectroscopy on feldspars - successes, limitations and their implications for remote sensing. Earth-Sci Rev 103:60-70

Hiesinger H, Helbert J, Co-I Team MERTIS (2010) The Mercury radiometer and thermal infrared spectrometer (MERTIS) for the bepicolombo mission. Planet Space Sci 58:144-165

Iiishi K, Tomisaka T, Katô T, Umegaki Y (1971) The force field of K feldspar. Z Kristallogr 134:213-229

Jolliff BL, Wieczorek MA, Shearer CK, Neal CR (eds) (2006) New Views of the Moon. Rev Mineral Geochem, vol 60. Mineral Soc Am, Chantilly. 784 pp

Kirkland L, Herr K, Keim E, Adams P, Salisbury J, Hackwell J, Treiman A (2002) First use of an airborne thermal infrared hyperspectral scanner for compositional mapping. Remote Sens Environ 80(3):447-459

Kroll H (1973) Estimation of the Al,Si distribution of feldspars from the lattice translations $\operatorname{Tr}[110]$ and $\operatorname{Tr}[1 \overline{1} 0]$. Contr Mineral Petrol 39:141-156

Kroll H, Knitter R (1991) Al,Si exchange kinetics in sanidine and anorthoclase and modeling of rock cooling paths. Am Mineral 76:928-941

Kroll H, Ribbe PH (1987) Determining (Al,Si) distribution and strain in alkali feldspars using lattice parameters and diffraction-peak positions: A review. Am Mineral 72:491-506

Kroll H, Schmiemann I, Von Cölln G (1986) Feldspar solid solutions. Am Mineral 71:1-16

Laves F, Hafner S (1956) Ordnung/Unordnung und Ultrarotabsorption I. (Al,Si)-Verteilung in Feldspäten. Z Kristallogr 108:52-63. https://doi.org/10.1524/zkri.1956.108.1-2.52

Malcherek T, Kroll H, Schleiter M, Salje E (1995) The kinetics of the monoclinic to monoclinic phase transition in $\mathrm{BaAl}_{2} \mathrm{Ge}_{2} \mathrm{O}_{8}$ feldspar. Phase Transit 55(1-4):199-215

Malcherek T, Carpenter M, Kroll H, Salje E (1999) Cation ordering in $\mathrm{BaAl}_{2} \mathrm{Ge}_{2} \mathrm{O}_{8}$-feldspar: implications for the phase transition in anorthite. Phys Chem Minerals 26:354-366

Martin RF (1970) Cell parameters and infrared absorption of synthetic high to low albites. Contrib Mineral Petrol 26:62-74

Nittler LR, Starr RD, Weider SZ, McCoy TJ, Boynton WV, Ebel DS, Ernst CM, Evans LG, Goldsten JO, Hamara DK, Lawrence DJ, McNutt Jr RL, Schlemm IICE, Solomon SC, Sprague AL (2011) The major-element composition of Mercury's surface from MESSENGER x-ray spectrometry. Science 333:1847-1850

Okrusch M, Matthes S (2014) Eine Einführung in die spezielle Mineralogie Petrologie und Lagerstättenkunde, 9th edn. Springer Spektrum, Berlin

Parsons I (1978) Feldspars and fluids in cooling plutons. Mineral Mag 42(321):1-17
Pieters CM, Englert PAJ (1993) Topics in Remote Sensing 4. Remote Geochemical Analysis: Elemental and Mineralogical Composition. Cambridge University Press

Ribbe PH (1983) Feldspar mineralogy. De Gruyter. Berlin, Boston

Rodriguez-Carvajal J (2005) Fullprof Suite Laboratoire Léon Brillouin (CEA-CNRS) CEA/Saclay, France

Salje EKH, Wruck B, Kroll H (1985) Thermodynamics of sodium feldspar II: Experimental results and numerical calculations. Phys Chem Minerals 12:99-107

Salje EKH, Carpenter MA, Malcherek T, Ballaran TB (2000) Autocorrelation analysis of infrered spectra from minerals. Eur $\mathrm{J}$ Mineral 12:503-519

Scambos TA, Smyth JR, McCormick TC (1987) Crystal-structure refinement of high sanidine from the upper mantle. Am Mineral 72(9-10):973-978

Solomon SC, Nittler LR, Anderson BJ (2018) Mercury: The View after MESSENGER. Cambridge University Press

Sprague AL, Nash DB, Witteborn FC, Cruikshank DP (1997) Mercury's feldspar connection - mid-ir measurements suggest plagioclase. Adv Space Res 19:1507

Sprague AL, Donaldson Hanna KL, Kozlowski RWH, Helbert J, Maturilli A, Warell JB, Hora JL (2009) Spectral emissivity measurements of mercury's surface indicate $\mathrm{Mg}$ - and Ca-rich mineralogy, K-spar, Na-rich plagioclase, rutile, with possible perovskite, and garnet. Planet Space Sci 57:364-383

Strob WD (1983) Strukturverfeierung eines Tief-Mikroklins, Zusammenhänge zwischen $<\mathrm{T}-\mathrm{O}>$ Abständen und $\mathrm{Al}$,Si-Ordnungsrad und metrische Variation in einer Tief-Albit/Tief-Mikroklin - Mischkristallreihe. Dissertation, Westfälische Wilhelms-Universität

Thomson JL, Salisbury JW (1993) The mid-infrared reflectance of mineral mixtures (7-14 $\mu \mathrm{m})$. Remote Sens Environ 45:1-13

Vincent RK, Thomson F (1972) Spectral compositional imaging of silicate rocks. J Geophys Res 77(14):2465-2472

Weber I, Morlok A, Grund T, Bauch KE, Hiesinger H, Stojic A, Grumpe A, Wöhler C, Klemme S, Sohn M, Martin DJP, Joy KH (2018) A mid-infrared reflectance database in preparation for space missions. In: Lunar and planetary science conference, p 1430

Wenk HR, Kroll H (1984) Analysis of P $\overline{1}, \mathrm{I} \overline{1}$ and $\mathrm{C} \overline{1}$ plagioclase structures. Bull Minéral 107(3-4):467-487

Wood JA, Dickey JJS, Marvin UB, Powell BN (1970) Lunar anorthosites. Science 167(3918):602-604

Zhang M, Wruck B, Graeme-Barber A, Salje EKH, Carpenter MA (1996) Phonon spectra of alkali feldspars; phase transitions and solid solutions. Am Mineral 81:92-104

Zhang M, Salje EKH, Carpenter MA, Parsons I, Kroll H, Reed SJB, Graeme-Barber A (1997) Exsolution and Al-Si disorder in alkali feldspars: Their analysis by infrared spectroscopy. Am Mineral 82(9-10):849-857

Publisher's note Springer Nature remains neutral with regard to jurisdictional claims in published maps and institutional affiliations. 